\title{
Protective Effects of Kinetin Against Pesticide Induced Toxicity ${ }^{\dagger}$
}

\author{
S. Rajasre Janane ${ }^{1}$, C. Sree Priyaa ${ }^{1}$, C. Valli Nachiyar ${ }^{1, *}$ \\ 1 Department of Biotechnology, School of Bio and Chemical Engineering. Sathyabama Institute of Science and Technology, \\ Chennai 600119 Tamil Nadu, India \\ * Correspondence: vnachiyar@gmail.com; \\ $\dagger$ Presented at International e-Conference on Bioengineering for Health and Environment (ICBHE 2020)
}

Received: 5.07.2020; Revised: 10.07.2020; Accepted: 12.07.2020; Published: 15.07.2020

\begin{abstract}
India, as a nation, is primarily dependent on agriculture not only as a means to feed its people but also the sector, which contributes almost $80 \%$ of the country's GDP. That being said, pesticides and fertilizers are enormously used to curb the pest attack against crops and to boost plant growth. It can be said that the negligent use of these chemicals may have side effects on the plants. We wanted to check the level of such side effects caused by acephate and also to find out whether such side effects can be neutralized by an organic and plant safe compound such as kinetin. Thus, in our project, we focused on checking the effects caused by the application of acephate, when sprayed (foliar) on to fenugreek plants. We performed three tests to study the oxidative stress, from which we can conclude that acephate by and of itself caused more oxidative stress whereas when applied in combination with Kinetin (lower acephate concentration and a comparatively higher concentration of Kinetin) the oxidative stress was comparatively low. Further studies were made in an animal model and cell lines. In the animal model, there was no significant result as both acephate and kinetin were inhibiting AChE activity. In Blood, the hemolysis percentage was calculated, and from the results, we could conclude that the combination of kinetin and acephate showed reduced hemolysis. When checked in cell lines, in fibroblast cells, the application of acephate increased the percentage of dead cells, whereas in combination with kinetin even-though there were initially some dead cells, the live cells that were remaining proliferated which can be viewed as the effect of kinetin. Whereas the cancerous cells of the sarcoma also had similar results, but the proliferation of the live cancerous sarcoma was more robust compared to the fibroblast cell, which could be inferred as a negative effect as it promotes cancerous growth. Thus, we can conclude that kinetin could be used as an ameliorative compound against pesticides by doing a few more extensive studies on various plant species and against various pesticides.
\end{abstract}

Keywords: pesticides; acephate; hemolysis; cancer.

(C) 2020 by the authors. This article is an open-access article distributed under the terms and conditions of the Creative Commons Attribution (CC BY) license (https://creativecommons.org/licenses/by/4.0/).

\section{Funding}

This research received no external funding.

\section{Acknowledgments}

This research has no acknowledgment.

\section{Conflicts of Interest}

The authors declare no conflict of interest.

https://conferenceproceedings.international 